\section{Positions Available}

\section{UNIVERSITY OF}

Cookson Professorship of Materials

The electors intend to proceed to an election of the Cookson Professorship of Materials with effect from 10ctober 1995. The stipend of the professorship is at present $£ 35,859$ per annum.

A non-stipendiary professorial fellowship at St Catherine's College is attached to the professorship.

Applications (ten copies, or one only from overseas candidates), naming three referees should be received not later than 27 March by the Registrar, University Offices, Wellington Square, Oxford OX1 2JD, England, from whom further particulars may be obtained.

The University is an Equal Opportunity Employer.

\section{GRADUATE FELLOWSHIP Michigan Technological University}

Graduate fellowship for research in applied experimental physics/materials science. Applied research in properties of aerospace coatings for earth-orbiting spacecraft, planetary spacecraft, and commercial jet aviation. Participation with NASA in-space experiments program. Good experimental skills and keen interest in space exploration and technology necessary. MS or PhD studies. Interdisciplinary academic program in Atmospheric Remote Sensing available. U.S. citizen or permanent visa. Women and minorities encouraged to apply. Contact J. Cordaro; Department of Physics; Michigan Technological University; Houghton, Ml 49931-1295. Internet jcordaro@phy.mtu.edu.

Michigan Technological University is an equal opportunity educational institution/equal opportunity employer.

\title{
Services Available
}

TRANSLATION of journal articles, patents reports, manuals, etc. from German and French into English by experienced materials specialist. Outstanding quality, fast turnaround, competitive rates. For more information call Nicholas Hartmann (708) 524-1191 or fax (708) 524-1355.

\section{Out of Order}

No ordinary article is order of any form. Noticed more in short supply. Now short's become the norm. Take solace that for every "out of order" sign you see, well-planned obsolescence helps the nation's GDP. A private under orders chafes against his yoke. Generals placing orders leave civil programs broke. Marvel at the orders of magnitude between atoms in the STM and cosmos yet unseen. Law and order is the code for measures that fight crime, a form of indecorum bred in inner city grime. Laws however do far more than carved stone tablets preach. They're how our legislatures invariably reach the lining of our purses and redistribute wealth to good works such as science and West Virginia's health. Our legislators have now stood order on its head by demanding answers well before the question's even read. Technology is, it seems, good for all our woes, so invent that product now before anyone even knows the fundamental science that feeds the enterprise but looks like an entitlement in budget cutters' eyes. As night does surely follow day, that is election day, the only sure result is priorities go astray. Marching orders wrong way round from off the very Hill where rules of Robert, one would think, should govern every bill. The point of order is to stop the funding of a table top while allocating to the dregs the source of funding for the legs. Perhaps a quote* or two will help the Members of this order to navigate their way back home across the beltway border:

"Whether these forms be in all cases the most rational or not is really not of so great importance" when it's money they allot.

"It is much more material that there should be a rule to go by than

what that rule is" lest research funding have no plan,

"[t]hat there may be a uniformity of proceeding in business, not

subject to the caprice of the chairman" or with malice toward research

begot.

"[N]or [subject to the] captiousness of the members" who can't loot

the treasure that is science yet expect to reap its fruit.

"It is very material that order be preserved"

and science in the vanguard is the order most deserved.

To first order it appears a point of little note, that there are rules through debate leading to a vote, but in order to relieve our field of long-term doubt, order must be restocked so it never again runs out.

E.N. KAUFMANN

*from Henry M. Robert, Robert's Rules of Order (1915 edition) as reprinted in Robert's Rules of Order Revised (William Morrow and Company, New York, 1971) p. 14. 